\title{
Analysis of industrial reactive powders flow properties at high temperature
}

\author{
Domenico Macrì $^{\mathbf{a}^{*}}$, Massimo Poletto ${ }^{\mathrm{b}}$, Diego Barletta ${ }^{\mathrm{b}}$, Stephen Sutcliffe ${ }^{\mathrm{c}}$, Paola Lettieri ${ }^{\mathrm{a}}$, \\ ${ }^{\text {a }}$ Department of Chemical Engineering, University College London, London WC1E 7JE, UK \\ ${ }^{\mathrm{b}}$ Dipartimento di Ingegneria Industriale, Università degli Studi di Salerno, Via Giovanni Paolo II, 132-I-84084 \\ Fisciano (SA), Italy \\ ${ }^{\mathrm{c}}$ Huntsman Pigments and Additives, Wynyard Park, Stockton-on-Tees, TS22 5FD, UK \\ *Corresponding author; Tel. 020 76797868; E-mail address: domenico.macri.14@ucl.ac.uk
}

\begin{abstract}
Changes of bulk flow properties of two different types of titanium dioxide powders were measured at room temperature and $500{ }^{\circ} \mathrm{C}$ using the High Temperature Annular Shear Cell. A significant increase of the macroscopic bulk flow properties was observed with increasing temperature, in particular with regard to the unconfined yield strength. A theoretical modelling procedure was proposed with the aim to relate the measured properties to the microscopic interactions between particles. The results indicated that the model might provide a good match with the experimental data if proper values for the model's parameters are taken into account.
\end{abstract}

Key-words: powder flowability, powder rheology, fluidization, interparticle forces

\section{Introduction}

Changes with temperature of flow properties of particulate solids are usually observed in many industrial process units, such as fluidized beds. However, a satisfactory understanding of the phenomena that are responsible for such modifications has not been achieved yet. Although a number of research works have been carried out on the influence of process conditions on fluidization, findings are still controversial, as reported by Yates [1] and Lettieri and Macri' [2] in their reviews on the subject. Much of the controversy still remains because the relative importance of the interparticle forces (IPFs) and the hydrodynamic forces (HDFs) on the flow behaviour of the particles.

Most of the disagreement on the relative role of HDFs and IPFs on the fluidizability of powders lies in the uncertain nature on the IPFs involved and in the difficulty of measuring them directly. Several authors investigated powders flow behaviour at different temperature through fluidization tests [3-7] and measurements of interactive forces between particles [8- 
12]. However, a full understanding of the effect of temperature on interparticle interactions and flow properties of bulk solid is still challenging.

Within this framework, powder rheology represents an appealing tool to evaluate indirectly the effects of the IPFs on fluidization. A great deal of research has been carried out over the last sixty years in order to define and measure, by means of simple tests, parameters apt to characterize and predict the flow properties of solid materials [13-15].

Powder flow behaviours are commonly described in engineering science by using a continuum mechanics methodology, which allows to directly characterize powder rheological properties and flowability by estimating the stress distribution within powders. Many testers are available to this aim, but shear cells are currently the most used devices [16].

Some works attempted to find a link between fluidization and rheological behaviour combining cohesion and flowability changes measured with shear testes to the fluidization behaviour of powders [17-21]. Powder cohesion can be related to the intensity of IPFs such as van der Waals, electrostatic and capillary forces, which are affected by temperature as a result of changes of particle hardness, liquid bridge formation or variations of the dielectric characteristics. However, a more systematic assessment of the independent and the combined effects of process conditions on fluid bed rheology and fluidization still needs to be accomplished.

Other works focused on the evaluation of the effect of temperature on the powder flow properties [22-24]. Tomasetta and co-workers [25-27] recently modified at the University of Salerno a Schulze shear cell (High Temperature Annular Shear Cell, HTASC) to perform measurements up to $500{ }^{\circ} \mathrm{C}$.

Even in condition at which electrostatic effects can be neglected, the effect of temperature on the powder flow properties is clearly a function of the material, in fact, temperature may produce phase changes which may determine or alter the amount of liquid available on the particle surface and turn on and off capillary forces. With the HTASC, Tomasetta and coworkers [25-27] evaluated rheological properties at ambient and high temperature for different powder samples: glass beads, FCC powder, fly ashes, alumina and natural corundum. The results showed that there was no significant effect of the temperature in the range $20-500{ }^{\circ} \mathrm{C}$ on the shear flow of the FCC powder, alumina, fly ashes and corundum powder. Instead, an increase of cohesion and, therefore, of the unconfined yield strength was observed with temperature for glass beads. More recently, Chirone et al. [28] used the hightemperature annular shear cell developed by Tomasetta and co-workers to characterize the bulk flow properties of five ceramic powder samples with different particle size distributions 
between ambient temperature and $500{ }^{\circ} \mathrm{C}$. They observed a significant increase of powder cohesion at $500{ }^{\circ} \mathrm{C}$ for different cuts of the same powder with a particle size larger than 20 $\mu \mathrm{m}$, resulting in a lower flowability of the samples. In both cases above, direct observation excluded the significance of electrostatic forces. Furthermore, within the range of temperature explored, the presence of capillary forces could also be excluded and, therefore, any observed variation of powder flow properties had to be explained considering only the action of van der Waals forces. The analysis tool used in both cases above was the model based on the multiscale approach proposed by Rumpf and Molerus [29-31] to predict the effect of temperature on the tensile strength of the powder samples. The main conclusion was that the temperature effects for materials in these conditions could only be explained by assuming a plastic deformation of the particle at the contact points.

Within this framework, this work presents further experimental observations reporting the effect of temperature on the flow behaviour of various titanium ore powders. To this end, rheological measurements were performed using the HTASC to assess the particle-particle interactions at both ambient and high temperature. Furthermore, in this paper, in place of the purely plastic deformation model suggested by Molerus [29], a novel procedure to correlate microscopic interparticle forces to the measured macroscopic bulk flow properties is proposed. This is based on the theoretical modelling approach proposed by Tomas [32,33] that was developed to account for elastic-plastic particle deformation at the contact points. The data will be discussed in order to assess on the best physical parameter to be considered to describe the material yield at the contact point.

\section{Theoretical framework}

In order to relate the microscopic interparticle interactions to bulk flow properties, the model proposed by Tomas $[32,33]$ for steady-state flow criterion of particles can be followed. Such theory is based on the possibility to relate consolidation and non-rapid flow of particulate solids with adhesion forces in particles contacts. The following main assumptions are considered:

1. Particles are organised in a randomly packed assembly and the packing structure is assumed to be isotropic with uniform porosity $(\varepsilon)$ in any cross-sectional areas as well as in the powder bulk;

2. Particles are spherical and monodisperse and thus the contact points are uniformly distributed over the particle surface with equal probability; 
3. The contact areas are small in comparison to the characteristic particle size, therefore these may be considered as contact points;

4. The transmission of an isostatic state of compressive stress with three equal principal stresses is assumed.

These hypotheses are the basis of the equation derived by Molerus [29] for the relationship between stresses and contact forces for monodisperse particles with characteristic particle size $\mathrm{d}$ and assembly porosity $\varepsilon$. In particular it is used to relate the interparticle forces acting in a real bulk solid, $\mathrm{F}_{\mathrm{H}}$, to the isostatic tensile strength, $\sigma_{\mathrm{t}}$, extrapolated from the powder experimental yield locus, i.e. the tensile stress at which the force necessary for the contact separation equals the adhesive interparticle force $F_{H}$ at the contact point:

$$
\mathrm{F}_{\mathrm{H}}=\sigma_{\mathrm{t}} \mathrm{d}_{\mathrm{sv}}^{2} \frac{\varepsilon}{1-\varepsilon}
$$

In Eqn. (1) $d_{s v}$ is the particle Sauter mean diameter, that provides the best estimate of the ratio between particle surface and volume and, therefore it gives the most accurate volumetric concentration of the interparticle contact points, which is the key variable to relate stresses to average interparticle forces values [27].

Tomas [32,33] considered an elastic-plastic particle contact model in order to describe the failure/flowability conditions of a bulk powder. He proposed the following equation for the quantification of the IPFs:

$$
\mathrm{F}_{\mathrm{H}}=(1+\kappa) \mathrm{F}_{\mathrm{H} 0}+\kappa \mathrm{F}_{\mathrm{N}}
$$

In which $\mathrm{F}_{\mathrm{N}}$ is the compressive normal force transmitted at the contact during the consolidation stage; $\mathrm{F}_{\mathrm{H} 0}$ is the adhesion force without any consolidation $\left(\mathrm{F}_{\mathrm{N}}=0\right)$ and any contact deformation intrinsically present in fine powders and related to their cohesive nature; $\kappa$ is the so-called elastic-plastic consolidation coefficient.

According to Tomas and Molerus, the value of $\mathrm{F}_{\mathrm{N}}$ can be calculated from the normal stress at consolidation $\sigma_{\mathrm{N}}$ applying the Rumpf equation:

$$
\mathrm{F}_{\mathrm{N}}=\sigma_{\mathrm{N}} \mathrm{d}_{\mathrm{sv}}^{2} \frac{\varepsilon}{1-\varepsilon}
$$

The coefficient $\kappa$ describes the influence of plastic contact deformation and so it is a measure of the irreversible particle contact stiffness or softness. It is given by the slope of the linear relationship between the interparticle adhesive force $F_{H}$ and the normal force $F_{N}$ : a small slope $\left(\mathrm{F}_{\mathrm{H}} \approx \mathrm{F}_{\mathrm{H} 0}\right)$ stands for low adhesion level because of stiff particle contacts, while a large inclination means soft contacts and a resulting cohesive flow behaviour. However, from a physical point of view, it is defined as: 


$$
\kappa=\frac{\kappa_{\mathrm{p}}}{\kappa_{\mathrm{A}}-\kappa_{\mathrm{p}}}
$$

Where $\kappa_{p}$ is the plastic repulsion coefficient and $\kappa_{A}$ is the elastic-plastic contact area coefficient representing the ratio of plastic particle deformation area, $A_{p l}$, to the total contact deformation area, which includes the contact area affected by elastic displacement, $A_{c}=A_{p l}$ + Ael. According to Tomas [32,33], they can be estimated as:

$$
\begin{gathered}
\kappa_{\mathrm{p}}=\frac{\mathrm{C}_{\mathrm{H}, \mathrm{sfs}}}{6 \pi \mathrm{p}_{\mathrm{f}} \mathrm{z}_{0}^{3}} \\
\kappa_{\mathrm{A}}=\frac{2}{3}+\frac{1}{3} \frac{\mathrm{A}_{\mathrm{pl}}}{\mathrm{A}_{\mathrm{c}}}=1-\frac{1}{3} \sqrt[3]{\frac{\mathrm{h}_{\mathrm{C}, \mathrm{f}}}{\mathrm{h}_{\mathrm{C}}}}
\end{gathered}
$$

Where $\mathrm{C}_{\mathrm{H}, \mathrm{sfs}}$ is the Hamaker solid-fluid-solid constant, $\mathrm{z}_{0}$ is the characteristic molecular separation distance, that amounts to about 0.3-0.4 $\mathrm{nm}$ [34], $\mathrm{p}_{\mathrm{f}}$ represents the repulsive particle micro-hardness, i.e. the resistance against plastic deformation expressed as the plastic compressive yield strength of the particle material. In addition, $\mathrm{h}_{\mathrm{C}}$ represents the particle height of flattening and $\mathrm{h}_{\mathrm{C}, \mathrm{f}}$ is the height of flattening for incipient yielding at $\mathrm{p}=\mathrm{p}_{\mathrm{f}}$ that can be defined as function of the particle size, the material Poisson ratio $v$ and the Young's modulus E. The parameter $\mathrm{h}_{\mathrm{C}, \mathrm{f}}$ is a function of the contact properties and can be estimated by means of the following equation:

$$
\mathrm{h}_{\mathrm{C}, \mathrm{f}}=\mathrm{d}_{\mathrm{sv}}\left(\frac{\pi \mathrm{p}_{\mathrm{f}}\left(1-\mathrm{v}^{2}\right)}{2 \mathrm{E}}\right)^{2}
$$

The parameter $\mathrm{h}_{\mathrm{C}}$ is a function of the forces acting at the contact loading:

$$
\mathrm{F}_{\mathrm{H} 0}+\mathrm{F}_{\mathrm{N}}-\frac{\pi}{4} \mathrm{~d}_{\mathrm{sv}} \mathrm{p}_{\mathrm{f}} \mathrm{h}_{\mathrm{C}}\left(1-\kappa_{\mathrm{p}}-\frac{1}{3} \sqrt[3]{\frac{\mathrm{h}_{\mathrm{C}, \mathrm{f}}}{\mathrm{h}_{\mathrm{C}}}}\right)=0
$$

The normal stress at consolidation, $\sigma_{N}$, was used to estimate the normal contact force $F_{N}$ with Eqn. (3), assuming a uniform distribution of powder consolidation at contact points. This assumption could be criticised by arguing that not all of the contact points are equally loaded, but as reported and demonstrated by Tomasetta et al. [27], a non-uniform distribution of consolidation forces at contact points does not introduce variations in the estimates of the tensile strength $\sigma_{\mathrm{t}}$ with the procedures discussed below.

Tomas proposed an alternative way to estimate elastic-plastic consolidation coefficient $\kappa$ using the experimental stationary yield locus (SYL) parameters:

$$
\kappa=\frac{\tan \phi_{\mathrm{st}}}{\tan \phi_{\mathrm{i}}}-1
$$


Where $\phi_{\mathrm{i}}$ is the angle of internal friction of the standard yield locus and $\phi_{\mathrm{st}}$ is the stationary angle of internal friction. While the standard yield loci (YL) describe the limits of incipient plastic deformation during consolidation and flow, the stationary yield locus (SYL) is the envelope of Mohr circles for steady-state flow with a certain negative intersection of the abscissa, $\sigma_{0}$, that is the isostatic tensile strength of unconsolidated powder. Both $\phi_{\text {st }}$ and $\sigma_{0}$ can be estimated from the experimental flow function data:

$$
\mathrm{f}_{\mathrm{c}}=\frac{2\left(\sin \phi_{\mathrm{st}}-\sin \phi_{\mathrm{i}}\right)}{\left(1+\sin \phi_{\mathrm{st}}\right)\left(1-\sin \phi_{\mathrm{i}}\right)} \sigma_{1}+\frac{2 \sin \phi_{\mathrm{st}}\left(1+\sin \phi_{\mathrm{i}}\right)}{\left(1+\sin \phi_{\mathrm{st}}\right)\left(1-\sin \phi_{\mathrm{i}}\right)} \sigma_{0}
$$

Moreover, the isostatic tensile strength $\sigma_{0}$ of an unconsolidated powder having characteristic diameter $\mathrm{d}$ and without any particle contact deformation can be related to the adhesion force $\mathrm{F}_{\mathrm{H} 0}$ and the initial porosity $\varepsilon_{0}$ of loose packing as proposed by Molerus [30]:

$$
\sigma_{0}=\frac{\mathrm{F}_{\mathrm{H} 0}}{\mathrm{~d}^{2}} \frac{1-\varepsilon_{0}}{\varepsilon_{0}}
$$

The theory proposed by Tomas promotes therefore the estimation and the characterization of flow properties of fine powders using an elastic-plastic contact consolidation coefficient $(\kappa)$, which is related to the particle material characteristics and increase with increasing interparticle adhesive forces. As a result, values of this coefficient estimated by means of powder shear tests can be used to understand and characterize the flow behaviour of powders. To this aim, Tomas proposed a direct correlation between $\kappa$ and the Jenike flowability factors $\mathrm{ff}_{\mathrm{c}}[35]$ :

$$
\kappa=\frac{1+\left(2 \mathrm{ff}_{\mathrm{c}}-1\right) \sin \phi_{\mathrm{i}}}{\tan \phi_{\mathrm{i}}\left(2 \mathrm{ff}_{\mathrm{c}}-1+\sin \phi_{\mathrm{i}}\right)} \sqrt{\frac{1}{1-\left(\frac{1+\left(2 \mathrm{ff}_{\mathrm{c}}-1\right) \sin \phi_{\mathrm{i}}}{2 \mathrm{ff}_{\mathrm{c}}-1+\sin \phi_{\mathrm{i}}}\right)^{2}}}-1
$$

Table 1 shows such a relationship between flowability and elastic-plastic contact consolidation coefficient for a typical angle of internal fraction of $30^{\circ}$.

Table 1 - Flowability assessment and $\kappa$ calculated by Eqn. (12) according to Tomas theory [36]

\begin{tabular}{lllll}
\hline Flowability factors $f f_{c}$ & $\kappa$ value & $\phi_{\text {st }}\left[{ }^{\circ}\right]$ & Evaluation & Examples \\
\hline $100-10$ & $0.01-0.107$ & $30.3-33$ & Free flowing & Dry fine sand \\
$4-10$ & $0.107-0.3$ & $33-37$ & Easy flowing & Moist fine sand \\
$2-4$ & $0.3-0.77$ & $37-46$ & Cohesive & Dry powder \\
$1-2$ & $0.77-\infty$ & $46-90$ & Very cohesive & Moist powder \\
$\leq 1$ & $\infty$ & - & Non flowing & Hydrated powder \\
\hline
\end{tabular}




\section{Materials and methods}

A Schulze Ring Shear Tester bench RST-01 has been used as a reference apparatus [37] to characterize the flow properties of the materials at ambient and high $\left(500{ }^{\circ} \mathrm{C}\right)$ temperature. A standard Type $S$ cell has been used at ambient temperature, while, to perform measurements of the powder flow properties at high temperature the cell modified by Tomasetta et al. [26] has been used. The experimental procedure used to evaluate the flow properties of the material follows the standard shear tests procedure proposed by Schulze [38]. Tomasetta demonstrated the equivalence of the experimental measurements performed by the modified and the original Schulze shear cell.

In the Schulze tester, the lid is held in place and the through rotates determining a shear plane inside the material. Two load cells measure the torque necessary to keep the lid in place. A normal stress to the shear plane is applied by loading the lid with a certain weight. The tester is provided with a system able to balance the lid weight and therefore the normal stress is calculated as the weight loaded defined by the cell surface. The shear stress is determined by the torque necessary to keep the lid in place and the surface of the shear plane.

The stress distribution inside the bulk solid is then analysed by combining Yield Locus and Mohr circles analysis. The Yield Locus analysis is aimed to determine the limiting shear stresses under any normal stress when failure, or to be precise, flow occurs. It is designed to evaluate the angle of internal friction, $\phi_{\mathrm{I}}$, and the cohesion, $\mathrm{C}$, of the sample material and then calculate its overall strength under compressive load. Assuming that the particles behaves like a solid in the failure conditions, the local state of stresses can be represented in the normal-shear stresses plane ( $\sigma-\tau$ plane) by Mohr's circles tangent to the yield locus. They can be used to evaluate the major principal stress, $\sigma_{1}$, and the unconfined yield stress, fc [38,39]. For Coulomb materials the standard yield locus is represented by a line and it is calculated as the best fitting line through the $(\sigma, \tau)$ experimental yield points obtained for a certain consolidation. The yield locus line is defined by the angle of internal friction $\phi_{\mathrm{i}}$, related to the line slope $\mu_{\mathrm{i}}$ as $\mu_{\mathrm{i}}=\tan \phi_{\mathrm{i}}$, and the cohesion $\mathrm{C}$, the line intercept. Within the coulomb hypotheses the tensile strength $\sigma_{\mathrm{t}}$ according to Schulze assumptions:

$$
\sigma_{\mathrm{t}}=\frac{\mathrm{C}}{\tan \phi_{\mathrm{i}}}
$$

The shear tests were carried out with the same sample of powder to measure three or four different yield loci and in turn to obtain a flow function with three or four points. Each 
measurement was repeated at least three times for all of the materials at every operative condition, in order to increase the statistical significance of the results in terms of yield loci.

In the present work, the tests were carried for a major principal stress $\sigma_{1}$ in the range $1-2$ $\mathrm{kPa}$. Such low normal stress values were adopted in order to approach a consolidation state relevant to fluidised powders. In fact, fluidization experiments will be performed in future work of the present project.

Two different types of titanium dioxide powders $\left(\mathrm{TiO}_{2}\right.$, rutile phase) supplied by Huntsman Pigments and Additives were chosen as experimental materials. In particular a synthetic rutile powder (SR) and a natural rutile powder (NR) have been used. The properties of these materials are listed in Table 2, including particle densities, bulk densities and assembly porosities at ambient temperature, Sauter mean diameters (SMD or $\mathrm{d}_{\mathrm{sv}}$ ) and particle size distributions by weight (PSD). Bulk densities and assembly porosities were calculated from data supplied from the Schulze apparatus. SMD and PSD were determined by sieve analysis and the $16^{\text {th }}$, the $50^{\text {th }}$ and the $84^{\text {th }}$ percentile sizes $\left(\mathrm{d}_{16}, \mathrm{~d}_{50}\right.$ and $\mathrm{d}_{84}$ respectively) are reported.

Table 2 - Samples main properties

\begin{tabular}{llllllll}
\hline Sample & $\rho_{\mathrm{p}}\left[\mathrm{kg} / \mathrm{m}^{3}\right]$ & $\rho_{\mathrm{b}\left(25^{\circ}\right)}\left[\mathrm{kg} / \mathrm{m}^{3}\right]$ & $\varepsilon_{\left(25^{\circ}\right)}[-]$ & $\mathrm{d}_{16}[\mu \mathrm{m}]$ & $\mathrm{d}_{50}[\mu \mathrm{m}]$ & $\mathrm{d}_{84}[\mu \mathrm{m}]$ & $\mathrm{d}_{\mathrm{sv}}[\mu \mathrm{m}]$ \\
\hline Synthetic Rutile (SR) & 3200 & 1500 & 0.53 & 122 & 162 & 212 & 145 \\
Natural Rutile (NR) & 4200 & 2320 & 0.45 & 117 & 202 & 379 & 155 \\
\hline
\end{tabular}

To analyse particle shapes and surfaces, optical microscope imaging of the samples was performed. The images from optical microscope in Figure 1 show rough surface and reasonably regular shapes for the synthetic rutile particles and they confirm the fairly wide particle size distribution measured by sieves technique. Figure 2 shows the images acquired for natural rutile powders. The sample exhibited very irregular shapes and rather smooth surfaces. Furthermore, such images confirm the large PSD observed with the sieves analysis. The roughness of the SR powder and the irregular shapes of the NR powder suggested that the local curvature radii at the contact points were considerably lower than the mean particle radii.
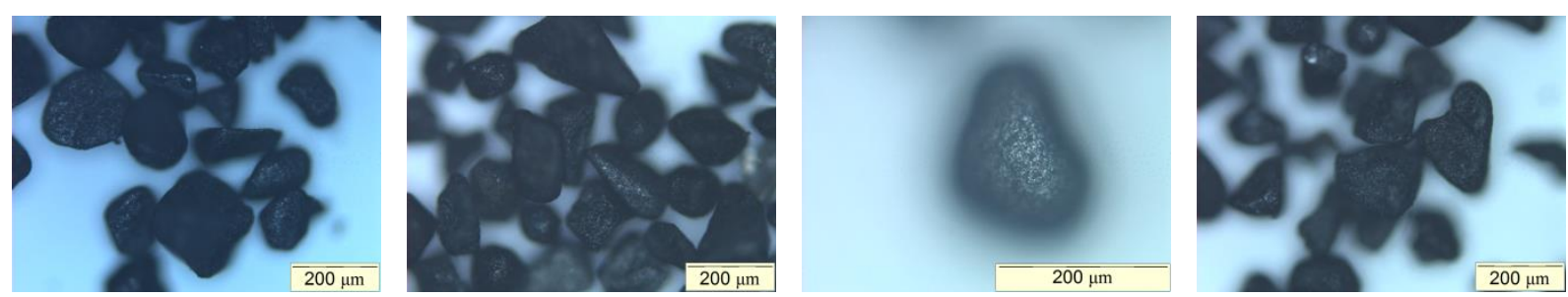

Figure 1 - Optical microscope images of synthetic rutile sample. 

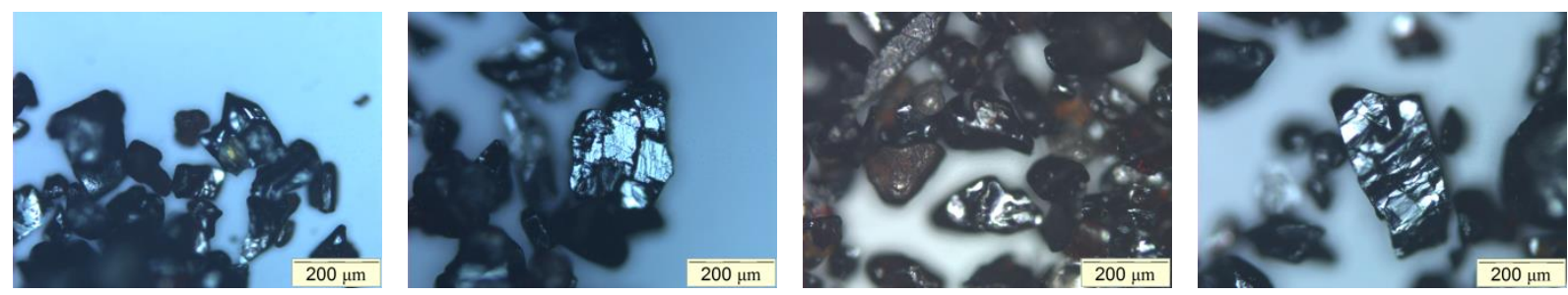

Figure 2 - Optical microscope images of natural rutile sample.

\section{Results and discussion}

\section{Experimental results}

The yield loci and the flow functions of the tested materials at ambient and high temperatures are reported in Figure 3. The main results in terms of major and minor principal stresses, consolidation stress, angle of internal friction, cohesion and tensile strength are listed in Table 3.

Table 3 - Results of the shear test performed with the Schulze apparatus

\begin{tabular}{|c|c|c|c|c|c|c|c|c|c|c|}
\hline Sample & $\mathrm{T}\left({ }^{\circ} \mathrm{C}\right)$ & Cell Type & YL & $\sigma_{1}(\mathrm{~Pa})$ & $\sigma_{2}(\mathrm{~Pa})$ & $\sigma_{\mathrm{N}}(\mathrm{Pa})$ & $\mathrm{C}(\mathrm{Pa})$ & $\phi_{\mathrm{i}}\left(^{\circ}\right)$ & $\sigma_{\mathrm{t}}(\mathrm{Pa})$ & $\mathrm{f}_{\mathrm{c}}(\mathrm{Pa})$ \\
\hline \multirow[t]{8}{*}{ Synthetic Rutile (SR) } & 25 & $\mathrm{~S}$ & 1 & 986 & 261 & 571 & 4 & 35.2 & 5.7 & 16 \\
\hline & & & 2 & 1200 & 310 & 696 & 5 & 35.9 & 6.9 & 19 \\
\hline & & & 3 & 1409 & 369 & 820 & 5 & 35.5 & 7.0 & 21 \\
\hline & & & 4 & 1633 & 431 & 944 & 6 & 35.3 & 8.5 & 25 \\
\hline & $\overline{500}$ & HT & 1 & 982 & 263 & 564 & 31 & 32.5 & 48.7 & 112 \\
\hline & & & 2 & 1215 & 310 & 688 & 33 & 34.0 & 48.9 & 126 \\
\hline & & & 3 & 1435 & 352 & 812 & 35 & 35.1 & 49.8 & 135 \\
\hline & & & 4 & 1689 & 414 & 936 & 40 & 35.2 & 56.7 & 153 \\
\hline \multirow[t]{7}{*}{ Natural Rutile (NR) } & 25 & S & 1 & 1151 & 252 & 603 & 9 & 39.2 & 11.0 & 39 \\
\hline & & & 2 & 1353 & 295 & 728 & 10 & 39.3 & 12.2 & 44 \\
\hline & & & 3 & 1550 & 339 & 852 & 11 & 39.3 & 13.4 & 46 \\
\hline & $\overline{500}$ & HT & 1 & 1055 & 271 & 590 & 16 & 34.8 & 23.0 & 61 \\
\hline & & & 2 & 1264 & 322 & 714 & 17 & 35.3 & 24.0 & 65 \\
\hline & & & 3 & 1502 & 363 & 838 & 18 & 36.6 & 24.2 & 72 \\
\hline & & & 4 & 1728 & 428 & 962 & 20 & 36.1 & 27.4 & 79 \\
\hline
\end{tabular}

The shear tests on the synthetic rutile powder were performed at low consolidation levels corresponding to major principal stresses in the range of approximately $1000-1700 \mathrm{~Pa}$. The corresponding yield loci at different levels of consolidation for tests at ambient and high temperatures are reported in Figure 3(a) and Figure 3(b), respectively.

A slight change in the cohesion and therefore in the tensile strength were observed with increasing consolidation stress, both at ambient and high temperature. A slight upward shift in the yield loci was instead observed from ambient to high temperature for a given consolidation level. Such a shift corresponds to an increase of C from $5 \pm 1$ to about $34.8 \pm 3$ $\mathrm{Pa}$ and of $\sigma_{\mathrm{t}}$ from $7 \pm 1$ to $51 \pm 3 \mathrm{~Pa}$.

The tests on the natural rutile were performed at low consolidation levels as well, which correspond to the same range for major principal stresses of synthetic rutile. The 
corresponding yield loci at different levels of consolidation for tests at ambient and high temperatures are reported in Figure 3(c) and Figure 3(d), respectively. Also for this powder, slight changes in the cohesion and in the tensile strength were observed with increasing consolidation stress, both at ambient and high temperature. However, as observed for the synthetic rutile, a slight upward shift in the yield loci was observed from ambient to high temperature for a given consolidation level, causing an increase of $\mathrm{C}$ from $10 \pm 1$ to about 18 $\pm 2 \mathrm{~Pa}$ and of $\sigma_{\mathrm{t}}$ from $12 \pm 1$ to $25 \pm 2 \mathrm{~Pa}$.

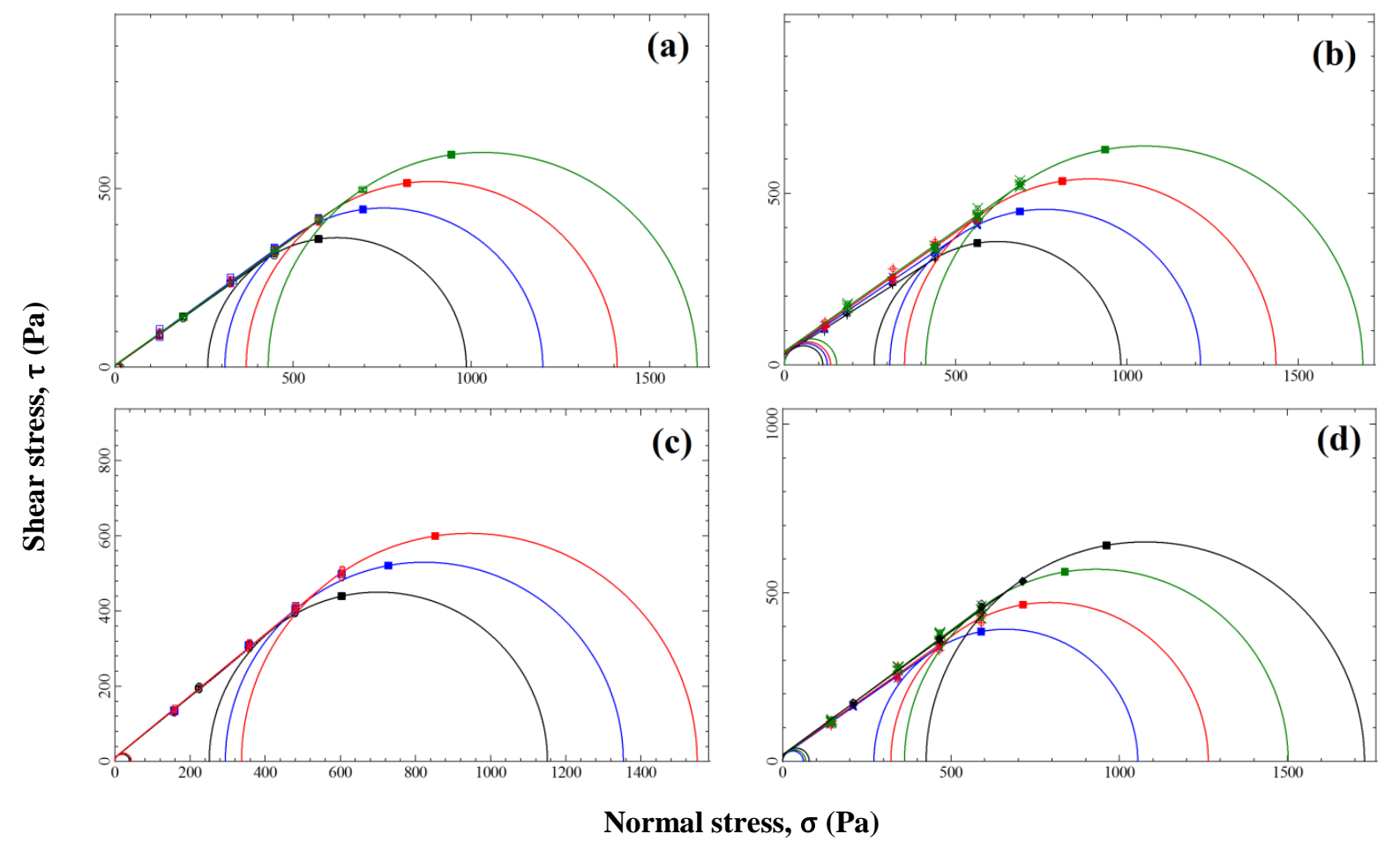

Figure 3 - Yield loci measured with the Schulze apparatus at ambient and high temperature and at different levels of consolidation. (a), (b) Synthetic rutile at $25{ }^{\circ} \mathrm{C}$ and $500{ }^{\circ} \mathrm{C}$ respectively. (c), (d) Natural rutile at $25{ }^{\circ} \mathrm{C}$ and $500{ }^{\circ} \mathrm{C}$ respectively. Filled symbols: experimental pre-shear data; hollow symbols: experimental shear data.

Figure 4 reports the flow functions of the two tested powder samples, according to Jenike's standard form and classification [35]. The inspection of the figure shows how the powders flowability is slightly influenced by temperature in the range explored. 


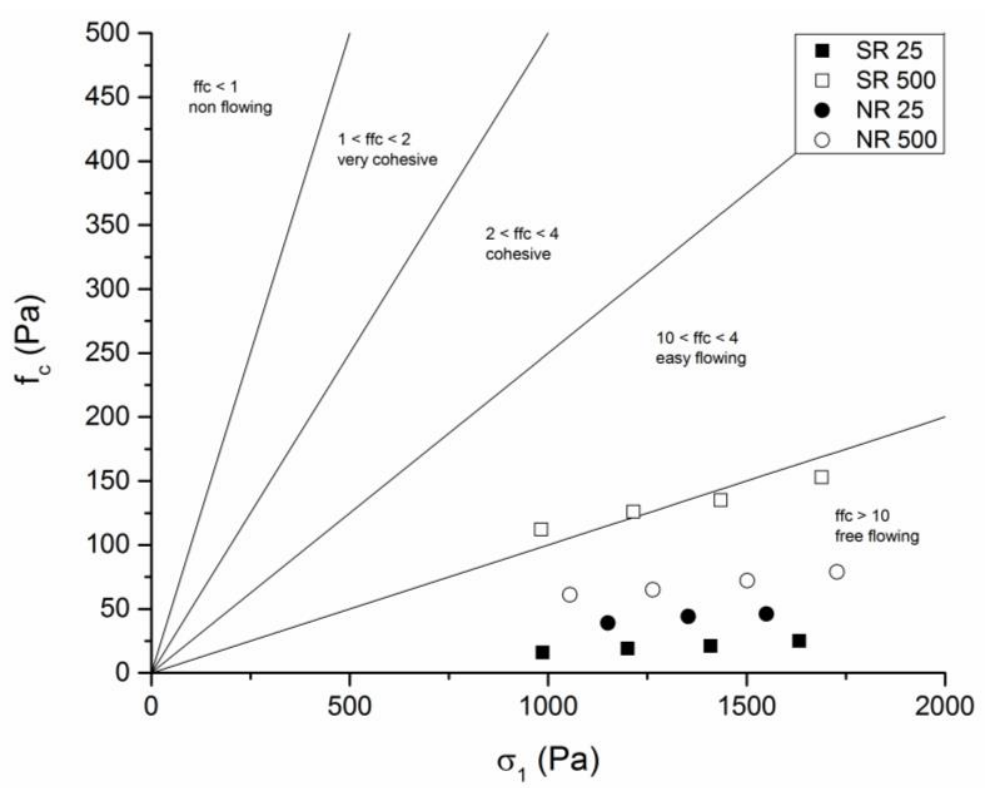

Figure 4 - Flow functions of the three tested powders measured with the Schulze apparatus at ambient and high temperatures.

\section{Models results}

With the aim to correlate the macroscopic powder flow properties with the forces that act between particles in the microscopic scale and to give an interpretation of the particleparticle contact mechanics a quantitative evaluation was performed. Sintering phenomena at particle contacts have been excluded from this analysis as the investigated temperatures are well below the material's melting point (estimated to be around $1850{ }^{\circ} \mathrm{C}$ ).

Before approaching the modelling, the occurring problems should be acknowledged. In particular the existing difficulty in identifying the accurate physical and mechanical properties of the materials at the different conditions investigated, such as the Hamaker constant and the compressive yield strength. According to Dzyaloshinskii et al. [40] the effect of the temperature on the Hamaker constant turns out to be completely unimportant since it is only affected by the dependence of the dielectric constant of the involved materials on temperature. As highlighted in some more recent studies, however, the Hamaker constant could increase with temperature in some materials in liquid form [41] or in form of nanoparticles [42], but no such effects of temperature on the Hamaker constant in micrometric particles of Titanium Dioxide are known yet. Instead, minor changes with temperature of the haymaker constant have been observed on similar materials. Therefore, a unique value of the Hamaker constant and of the characteristic molecular separation distance $\mathrm{z}_{0}$ were assumed for both the samples and temperatures, according to the value reported by Tomas for titanium dioxide [32]. 
In order to properly consider the thermal expansion and the thermal effects on mechanical properties of the particle material, different values of Young's modulus E [43,44], particle density $\rho_{\mathrm{p}}[45]$ and compressive yield strength $\mathrm{p}_{\mathrm{f}}[32,46]$ were adopted at $25^{\circ} \mathrm{C}$ and $500^{\circ} \mathrm{C}$. Experimental values of samples porosities and bulk densities, measured during shear tests with HT-ASC were also considered. The average main materials properties adopted in the present case study are listed in Table 4.

Table 4 - Samples main average properties

\begin{tabular}{|c|c|c|c|c|c|c|c|c|c|c|}
\hline Sample & $\begin{array}{l}\mathrm{T} \\
{\left[{ }^{\circ} \mathrm{C}\right]}\end{array}$ & $\begin{array}{l}\rho_{\mathrm{p}} \\
{\left[\mathrm{kg} / \mathrm{m}^{3}\right]}\end{array}$ & $\begin{array}{l}\rho_{\mathrm{b}} \\
{\left[\mathrm{kg} / \mathrm{m}^{3}\right]}\end{array}$ & $\begin{array}{l}\varepsilon \\
{[-]}\end{array}$ & $\begin{array}{l}\mathrm{C}_{\mathrm{H}, \mathrm{sfs}} \\
{\left[10^{-20} \mathrm{~J}\right]}\end{array}$ & $\begin{array}{l}\mathrm{z}_{0} \\
{[\mathrm{~nm}]}\end{array}$ & $\begin{array}{l}\mathrm{E} \\
{[\mathrm{GPa}]}\end{array}$ & $\begin{array}{l}\mathrm{N} \\
{[-]}\end{array}$ & $\begin{array}{l}\sigma_{\mathrm{f}} \\
{[\mathrm{MPa}]}\end{array}$ & $\begin{array}{l}\mathrm{Hv} \\
{[\mathrm{GPa}]}\end{array}$ \\
\hline \multirow{2}{*}{ Synthetic Rutile (SR) } & 25 & 3200 & 1500 & 0.53 & 12.6 & 0.336 & 284.2 & 0.28 & 130 & 10 \\
\hline & 500 & 3120 & 1385 & 0.56 & 12.6 & 0.336 & 270.8 & 0.28 & 80 & 5 \\
\hline \multirow[t]{2}{*}{ Natural Rutile (NR) } & 25 & 4200 & 2320 & 0.45 & 12.6 & 0.336 & 284.2 & 0.28 & 130 & 10 \\
\hline & 500 & 4120 & 2050 & 0.50 & 12.6 & 0.336 & 270.8 & 0.28 & 80 & 5 \\
\hline
\end{tabular}

With regard to the compressive yield strength $\mathrm{p}_{\mathrm{f}}$, it is necessary to take into account that the local plastic deformation occurs under hindered conditions because of the surrounding material at the contact point. Hence, such a parameter is larger than the compressive yield strength usually measured under unhindered deformation conditions $\left(\sigma_{\mathrm{f}}\right)$ and reported in the literature. According to Tomasetta el al. [27], the correct value for $\mathrm{p}_{\mathrm{f}} \approx 3 \sigma_{\mathrm{f}}$ should be considered. Nevertheless, $\sigma_{\mathrm{f}}$ values at high temperature are hard to find in the literature and the reported values are often ambiguous and controversial. As observed for similar materials $[47,48]$ the compressive yield strength was considered to decrease with temperature and it was estimated as:

$$
\mathrm{p}_{\mathrm{f}, 500}=\alpha \mathrm{p}_{\mathrm{f}, 25}
$$

Where $\alpha$ is a proportional constant varying in the range 0.1-1 that relates $\mathrm{p}_{\mathrm{f}}$ at high temperature with the one at ambient temperature. However, in the present case study two different approaches were followed:

- according to the first, the value for the compressive yield strength at ambient conditions was considered equals to $400 \mathrm{MPa}$ as reported by Tomas [32] and an average values of $\alpha=0.6$ was used, as observed for similar materials $[47,48]$;

- according to the second, the Vickers Hardness $\left(\mathrm{H}_{\mathrm{V}}\right)$ of polycrystalline $\mathrm{TiO}_{2}$ reported by Guermazi et al. [46] as a function of temperature was considered as compressive yield strength.

The sample porosity $\varepsilon$ was estimated from Eqn. (15), using the values of particle densities (from powders data sheets) and bulk densities measured by the Schulze cell, both reported in Table 4. 


$$
\varepsilon=1-\frac{\rho_{\mathrm{p}}}{\rho_{\mathrm{b}}}
$$

This assessment is affected by some inaccuracies, because of the leakage of the powder from the cell during shear testing, as observed by Tomasetta et al. [27]. This leakage may entail an overestimation of the effective mass of the sample, and result in a certain underestimate of the relevant porosity calculated from the apparent bulk density (i.e., the ratio between the initial sample mass and the current sample volume). Moreover, the porosity estimated with this procedure is a volume-averaged value and it is not necessarily representative of the local porosity in the shear zone, which is more relevant to the measured stresses. In fact, powder dilation produced by the shear motion makes the local porosity in the shear zone larger than the sample average. However, as reported by Tomasetta et al. [27], changes in this parameter only slightly affect the model results.

The results obtained from the application of the mathematical model proposed by Tomas are reported in the following. The three different estimation procedure of $\kappa$, previously described, are both taken into account. The following notation will be used:

- $\kappa$ for value estimated using Eqn. (2)

- $\kappa^{*}$ for value estimated using Eqn. (9)

- $\kappa^{* *}$ for value estimated using Eqns (4) to (8)

Calculations for $\kappa$ and $\kappa^{* *}$ require the experimental values for $\mathrm{F}_{\mathrm{H}}, \mathrm{F}_{\mathrm{H} 0}$ and $\mathrm{F}_{\mathrm{N}}$ obtained by means of Eqns (2), (11), (3).

Experimental values of the cohesion and of the angle of internal friction were used to estimate the powder tensile strength $\sigma_{\mathrm{t}}$ according to Eqn. (13). Such a value was compared with the theoretical tensile strength value $\left(\sigma_{\mathrm{t}}^{*}\right)$ obtained by the application of the model proposed, Eqns. (6) to (1) in reverse order. Table 5 reports the estimated results for $\kappa, \kappa^{*}$ and $\kappa^{* *}$.

Figure 5 shows the comparison between the tensile strength values obtained by the application of the model and the experimental values. In the first case, despite the significant number of simplifying assumptions that were considered, the model gives reasonable estimates of $\kappa$ values at both investigated temperatures. It is also important to note that the estimation of $\kappa^{*}$ and $\sigma_{t}^{*}$ is independent of the compressive yield strength. As shown in Figure 5(a), even though the model seems to overestimate tensile strength value by $20 \%$, a quite good match is reached between model and experimental values. 
Table 5 - Main results of the Tomas mathematical models

\begin{tabular}{llllll}
\hline \multirow{2}{*}{ Sample } & $\mathrm{T}$ & $\kappa[-]$ & $\kappa^{*}[-]$ & \multicolumn{2}{c}{$\kappa^{* * *}[-]$} \\
\cline { 3 - 6 } & {$\left[{ }^{\circ} \mathrm{C}\right]$} & $\mathrm{F}_{\mathrm{H}}-\mathrm{F}_{\mathrm{N}}$ Slope & & $\mathrm{p}_{\mathrm{f}}$ from Tomas [32] & $\mathrm{p}_{\mathrm{f}}$ from Guermazi et al. [46] \\
\hline Synthetic Rutile & 25 & 0.007 & 0.010 & 1.437 & 0.018 \\
\hline Natural Rutile & 500 & 0.017 & 0.048 & 5.065 & 0.036 \\
\hline & 25 & 0.009 & 0.011 & 1.595 & 0.018 \\
\hline
\end{tabular}

On the other hands, the estimated values of $\kappa^{* *}$ using the coefficients $\kappa_{\mathrm{P}}$ and $\kappa_{\mathrm{A}}$ defined by Eqns. (5)-(6), are strongly dependent on the value of compressive yield strength considered. In order to overcome the problem of identifying the accurate value of the such a parameter, the model was implemented considering both Tomas [32] and Guermazi et al. [46] proposals for $\mathrm{p}_{\mathrm{f}}$. In Figure $5(\mathrm{~b})$ is reported the comparison between the tensile strength values obtained by the application of the model using $\kappa^{* *}$ as coefficient and the experimental values. It can be observed as with high values of $\mathrm{p}_{\mathrm{f}}$ a better match is reached between model and experimental data.

In addition, it is important to note that in the micro-mechanical model of Tomas [49] the contact areas among particles are considered to be perfectly spherical [50] and thus $\kappa^{* *}$ would deviate significantly from contacts in reality where spherical areas are seldom seen. This could explain why $\kappa$ back-calculated from shear tests and $\kappa^{* *}$ are different.
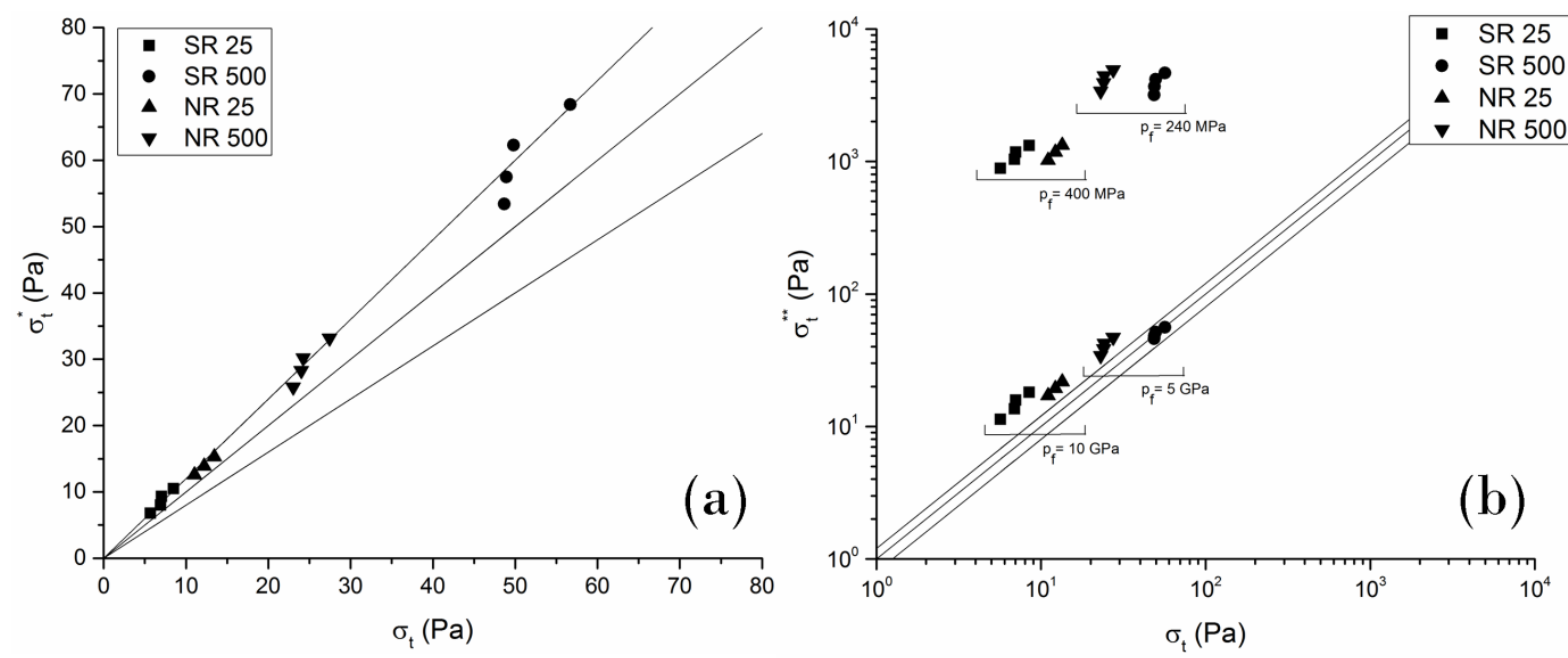

Figure 5 - Parity plot of tensile strength values obtained from experimental data versus values obtained from Tomas model using $\kappa^{*}(\mathrm{a})$ and $\kappa^{* *}(\mathrm{~b})$ as coefficient.

Therefore, the analysis shows that the Tomas modelling approach might provide good estimations of consolidation coefficient and theoretical tensile strength if reasonable values for the compressive yield strength are taken into account. Moreover, considering accurate changes in $p_{f}$ with temperature might explain the temperature effects observed during the experiments. In the light of these, a sensitivity analysis will be performed as future work in order to assess the effects of changes in compressive yield strength. 


\section{Conclusion}

Experimental examinations with Schulze shear cell were carried out in order to assess the rheological behaviour of the materials at ambient and with increasing temperature. Shear experiments highlighted a significant increase of unconfined yield strength with temperature, which means that a higher force is required to deform or break the material when it is not confined by a container. From the particulate material perspective, it means that a higher force is required to fail a consolidated mass of material to initialize flow. This resulted in a lower flowability of the samples.

A theoretical model based on the particle-particle approach proposed by Tomas was used to correlate the isostatic tensile strength of powders with the interparticle interaction forces. The comparison between experiments conducted at ambient and high temperatures and the theoretical model suggests that the proposed approach gives correct predictions for the tensile strength if the proper values for the material physical and mechanical properties, in particular for the compressive yield strength, at both ambient and high temperature are used. In fact, as highlighted by the conducted analysis, different $\mathrm{p}_{\mathrm{f}}$ values may yield better fits to the experimental data.

\section{Nomenclature}

\begin{tabular}{|c|c|c|c|}
\hline $\mathrm{C}$ & cohesion $(\mathrm{Pa})$ & SR & synthetic rutile sample \\
\hline$A_{c}$ & total contact deformation area $\left(\mathrm{m}^{2}\right)$ & SYL & stationary yield locus \\
\hline Ael & elastic particle deformation area $\left(\mathrm{m}^{2}\right)$ & $\mathrm{T}$ & temperature $\left({ }^{\circ} \mathrm{C}\right)$ \\
\hline$A_{\mathrm{pl}}$ & plastic particle deformation area $\left(\mathrm{m}^{2}\right)$ & YL & yield locus \\
\hline $\begin{array}{l}\mathrm{CH}_{\mathrm{H}, \mathrm{sfs}} \\
\mathrm{d}\end{array}$ & $\begin{array}{l}\text { Hamaker solid-fluid-solid constant }(\mathrm{J}) \\
\text { particle diameter }(\mathrm{m})\end{array}$ & $\mathrm{Z}_{0}$ & characteristic molecular separation distance $(\mathrm{m})$ \\
\hline$d_{16}$ & $16^{\text {th }}$ percentile size $(\mathrm{m})$ & $\alpha$ & ratio between $p_{f}$ at high $T$ and $p_{f}$ at ambient $T$ \\
\hline$d_{50}$ & $50^{\text {th }}$ percentile size $(\mathrm{m})$ & $\varepsilon$ & bed voidage $(-)$ \\
\hline$d_{84}$ & $84^{\text {th }}$ percentile size $(\mathrm{m})$ & $\varepsilon_{0}$ & fixed bed voidage (-) \\
\hline$d_{\mathrm{sv}}$ & Sauter mean diameter $(\mathrm{m})$ & $\kappa$ & elastic-plastic consolidation coefficient (-) \\
\hline $\mathrm{E}$ & Young modulus (N m-2) & $\kappa_{\mathrm{A}}$ & elastic-plastic contact area coefficient (-) \\
\hline $\mathrm{f}_{\mathrm{c}}$ & unconfined yield strength $(\mathrm{Pa})$ & $\kappa_{\mathrm{p}}$ & plastic repulsion coefficient for Tomas model (-) \\
\hline $\mathrm{ff}_{\mathrm{c}}$ & flow factor $(-)$ & $v$ & Poisson ratio (-) \\
\hline $\mathrm{F}_{\mathrm{H}}$ & adhesion force $(\mathrm{N})$ & $\rho_{\mathrm{b}}$ & powder bulk density $\left(\mathrm{kg} \mathrm{m}^{-3}\right)$ \\
\hline $\mathrm{F}_{\mathrm{H} 0}$ & $\mathrm{~F}_{\mathrm{H}}$ without any consolidation and flattening $(\mathrm{N})$ & $\rho_{\mathrm{p}}$ & particle density $\left(\mathrm{kg} \mathrm{m}^{-3}\right)$ \\
\hline $\mathrm{F}_{\mathrm{N}}$ & compressive normal force $(\mathrm{N})$ & $\sigma$ & normal stress $(\mathrm{Pa})$ \\
\hline HDFs & Hydrodynamic forces & $\sigma_{0}$ & isostatic tensile strength of unconsolidated \\
\hline $\mathrm{H}_{\mathrm{V}}$ & Vickers Hardness (Pa) & & powder $(\mathrm{Pa})$ \\
\hline $\mathrm{h}_{\mathrm{C}}$ & height of flattening (m) & $\sigma_{1}$ & major principal stress $(\mathrm{Pa})$ \\
\hline $\mathrm{h}_{\mathrm{C}, \mathrm{f}}$ & height of flattening at $\mathrm{p}=\mathrm{pf}(\mathrm{m})$ & $\sigma_{2}$ & minor principal stress $(\mathrm{Pa})$ \\
\hline IPFs & Interparticle forces & $\sigma_{\text {pre }}$ & normal pre-shear stress $(\mathrm{Pa})$ \\
\hline NR & natural rutile sample & $\sigma_{\mathrm{t}}$ & tensile strength $(\mathrm{Pa})$ \\
\hline $\mathrm{p}_{\mathrm{f}}$ & compressive yield strength $(\mathrm{Pa})$ & $\tau$ & shear stress $(\mathrm{Pa})$ \\
\hline $\mathrm{P}$ & Pressure $(\mathrm{Pa})$ & $\tau_{\text {pre }}$ & tangential pre-shear stress $(\mathrm{Pa})$ \\
\hline PSD & particle size distribution & $\phi_{\mathrm{i}}$ & angle of internal friction (deg.) \\
\hline RDS & relative diameter spread (-) & $\phi_{\text {st }}$ & steady-state angle of internal friction (deg.) \\
\hline
\end{tabular}




\section{References}

[1] J.G. Yates, Effects of temperature and pressure on gas-solid fluidization, Chem. Eng. Sci. 51 (1996) 168-205.

[2] P. Lettieri, D. Macrì, Effect of process conditions on fluidization, KONA Powder Part. J. 2016 (2016) 86-108. doi:10.14356/kona.2016017.

[3] H.Y. Xie, D. Geldart, Fluidization of FCC powders in the bubble-free regime: effect of types of gases and temperature, Powder Technol. 82 (1995) 269-277. doi:10.1016/0032-5910(94)02932-E.

[4] B. Formisani, R. Girimonte, L. Mancuso, Analysis of the fluidization process of particle beds at high temperature, Chem. Eng. Sci. 53 (1998) 951-961.

[5] P. Lettieri, J.G. Yates, D. Newton, The influence of interparticle forces on the fluidization behaviour of some industrial materials at high temperature, Powder Technol. 110 (2000) 117-127. doi:10.1016/S0032-5910(99)00274-0.

[6] P. Lettieri, D. Newton, J.G. Yates, High temperature effects on the dense phase properties of gas fluidized beds, Powder Technol. 120 (2001) 34-40. doi:10.1016/S0032-5910(01)00344-8.

[7] P. Lettieri, D. Newton, J.G. Yates, Homogeneous bed expansion of FCC catalysts, influence of temperature on the parameters of the Richardson-Zaki equation, Powder Technol. 123 (2002) 221-231. doi:10.1016/S0032-5910(01)00463-6.

[8] P. Pagliai, S.J.R. Simons, D. Rhodes, Towards a fundamental understanding of defluidisation at high temperatures: A micro-mechanistic approach, Powder Technol. 148 (2004) 106-112. doi:10.1016/j.powtec.2004.09.004.

[9] P. Pagliai, S.J.R. Simons, D. Rhodes, A novel experimental study of temperature enhanced cohesive interparticle forces, Powder Technol. 174 (2006) 71-74. doi:10.1016/j.powtec.2006.10.025.

[10] A.J. Forsyth, S. Hutton, M.J. Rhodes, Effect of cohesive interparticle force on the flow characteristics of granular material, Powder Technol. 126 (2002) 150-154. doi:10.1016/S0032-5910(02)00046-3.

[11] M. Tanaka, M. Komagata, M. Tsukada, H. Kamiya, Evaluation of the particle-particle interactions in a toner by colloid probe AFM, Powder Technol. 183 (2008) 273-281. doi:10.1016/j.powtec.2007.07.039.

[12] M.A.S. Quintanilla, A. Castellanos, J.M. Valverde, Correlation between bulk stresses and interparticle contact forces in fine powders., Phys. Rev. E. Stat. Nonlin. Soft Matter Phys. 64 (2001) 031301. doi:10.1103/PhysRevE.64.031301.

[13] J.M. Valverde, M. a. S. Quintanilla, A. Castellanos, P. Mills, The settling of fine cohesive powders, Europhys. Lett. 54 (2001) 329-334. doi:10.1209/epl/i2001-002464.

[14] J.M. Valverde, A. Castellanos, P. Mills, M.A.S. Quintanilla, Effect of particle size and interparticle force on the fluidization behavior of gas-fluidized beds., Phys. Rev. E. Stat. Nonlin. Soft Matter Phys. 67 (2003) 051305. doi:10.1103/PhysRevE.67.051305.

[15] U. Zafar, G. Calvert, C. Hare, M. Ghadiri, R. Girimonte, B. Formisani, M. a. S. Quintanilla, J.M. Valverde, Comparison of Cohesive Powder Flowability Measured by Schulze Shear Cell, Raining Bed Method, Sevilla Powder Tester and New Ball Indentation Method, Powder Technol. 2015 (2015) 807-816. 
doi:10.1016/j.powtec.2015.09.010.

[16] J.J. Schwedes, Review on testers for measuring flow properties of bulk solids, Granul. Matter. 5 (2003) 1-43. doi:10.1007/s10035-002-0124-4.

[17] G. Bruni, P. Lettieri, D. Newton, D. Barletta, An investigation of the effect of the interparticle forces on the fluidization behaviour of fine powders linked with rheological studies, Chem. Eng. Sci. 62 (2007) 387-396. doi:10.1016/j.ces.2006.08.059.

[18] D. Newton, G. Smith, N. Hird, Comments on experimental data on the suitability of assigning a viscosity to the fluidized bed dense phase, in: Unpubl. Pap. Present. Fifth Int. Conf. Fluid Part. Interact., 1999.

[19] K. Johanson, D. Barletta, The influence of air counter-flow through powder materials as a means of reducing cohesive flow problems, Part. Part. Syst. Charact. 21 (2004) 316-325. doi:10.1002/ppsc.200400939.

[20] G. Bruni, D. Barletta, M. Poletto, P. Lettieri, A rheological model for the flowability of aerated fine powders, Chem. Eng. Sci. 62 (2007) 397-407. doi:10.1016/j.ces.2006.08.060.

[21] G. Bruni, P. Lettieri, T. Elson, J. Yates, The effect of process conditions on the fluidization behaviour of gas fluidized beds, in: AIChE Annu. Meet., 2004: pp. 28152820 .

[22] M. Ripp, S. Ripperger, Influence of temperature on the flow properties of bulk solids, Chem. Eng. Sci. 65 (2010) 4007-4013. doi:10.1016/j.ces.2010.03.046.

[23] B. Zimmerlin, H. Leibold, H. Seifert, Evaluation of the temperature-dependent adhesion characteristics of fly ashes with a HT-rheometer, Powder Technol. 180 (2008) 17-20. doi:10.1016/j.powtec.2007.03.014.

[24] H. Kamiya, A. Kimura, T. Yokoyama, M. Naito, G. Jimbo, Development of a splittype tensile-strength tester and analysis of mechanism of increase of adhesion behavior of inorganic fine powder bed at high-temperature conditions, Powder Technol. 127 (2002) 239-245. doi:10.1016/S0032-5910(02)00117-1.

[25] I. Tomasetta, D. Barletta, M. Poletto, The Effect of Temperature on Flow Properties of Fine Powders, Chem. Eng. Trans. 24 (2011) 655-660.

[26] I. Tomasetta, D. Barletta, M. Poletto, The High Temperature Annular Shear Cell: A modified ring shear tester to measure the flow properties of powders at high temperature, Adv. Powder Technol. 24 (2013) 609-617. doi:10.1016/j.apt.2012.11.007.

[27] I. Tomasetta, D. Barletta, M. Poletto, Correlation of powder flow properties to interparticle interactions at ambient and high temperatures, Particuology. 12 (2014) 90-99. doi:10.1016/j.partic.2013.02.002.

[28] R. Chirone, D. Barletta, P. Lettieri, M. Poletto, Bulk flow properties of sieved samples of a ceramic powder at ambient and high temperature, Powder Technol. 288 (2016) 379-387. doi:10.1016/j.powtec.2015.11.040.

[29] O. Molerus, Theory of yield of cohesive powders, Powder Technol. 12 (1975) 259275.

[30] O. Molerus, Effect of interparticle cohesive forces on the flow behaviour of powders, Powder Technol. 20 (1978) 161-175. 
[31] H. Rumpf, Zur theorie der zugfestigkeit von agglomeraten bei kraftuebertragung an kontaktpunkten, Chemie Ing. Tech. 42 (1970) 538-540.

[32] J. Tomas, Particle Adhesion Fundamentals and Bulk Powder Consolidation, Kona. 18 (2000) 157-169.

[33] J. Tomas, Product design of cohesive powders - Mechanical properties, compression and flow behavior, Chem. Eng. Technol. 27 (2004) 605-618. doi:10.1002/ceat.200406134.

[34] H. Krupp, Particle adhesion theory and experiment, Adv. Colloid Interface Sci. 1 (1967) 111-239. doi:10.1016/0001-8686(67)80004-6.

[35] A.W. Jenike, Gravity flow of solids, Trans Instn Chem Engrs. 40 (1962) 264.

[36] J. Tomas, Fundamentals of cohesive powder consolidation and flow, Granul. Matter. 6 (2004) 75-86. doi:10.1007/s10035-004-0167-9.

[37] D. Schulze, Development and application of a novel ring shear tester - Entwicklung und Anwendung eines neuartigen Ringschergerätes, Aufbereitungs-Technik. 35 (1994) 524-535.

[38] D. Schulze, Powders and bulk solids: behavior, characterization, storage and flow, Berlin, 2007.

[39] R.M. Nedderman, Statics and Kinematics of Granular Materials, Cambridge University Press, 1992.

[40] I.E. Dzyaloshinskii, E.M. Lifshitz, L.P. Pitaevskii, General Theory of van der Waals' Forces, Sov Phys Usp. 4 (1961) 153-176. doi:10.1070/PU1961v004n02ABEH003330.

[41] A.J. Castellanos, M. Garcia-Sucre, G. Urbina-Villalba, Temperature dependence of hamaker constants for fluorocarbon compounds, J. Phys. Chem. B. 107 (2003) 85328537. doi:10.1021/jp022670s.

[42] K. Jiang, P. Pinchuk, Temperature and size-dependent Hamaker constants for metal nanoparticles, Nanotechnology. $27 \quad$ (2016) 345710. doi:10.1088/09574484/27/34/345710.

[43] B. Soediono, Elasticity, in: Mech. Prop. Ceram. Second Ed., John Wiley \& Sons, Inc., Hoboken, NJ, USA, 2009: pp. 35-54. doi:10.1002/9780470451519.ch3.

[44] J.B. Wachtman, W.E. Tefft, D.G. Lam, C.S. Apstein, Exponential temperature dependence of Young's modulus for several oxides, Phys. Rev. 122 (1961) 17541759. doi:10.1103/PhysRev.122.1754.

[45] R.K. Kirby, Thermal Expansion of Rutile from 100 to $700^{\circ} \mathrm{K}$, J. Res. Natl. Bur. Stand. (1934). 71A (1967) 363-369. doi:10.6028/jres.071A.041.

[46] M. Guermazi, H.J. Hofler, H. Hahn, R.S. Averback, Temperature Dependence of the Hardness of Nanocrystalline Titanium Dioxide, J. Am. Ceram. Soc. 74 (1991) 26722674. doi:10.1111/j.1151-2916.1991.tb06819.x.

[47] J.P. Poirier, Creep of crystals: high-temperature deformation processes in metals, ceramics and minerals, Cambridge University Press, 1985.

[48] D. Weidner, Y. Wang, M.T. Vaughan, Yield strength at high pressure and temperature, Geophys. $\quad$ Res. $\quad$ Lett. $21 \quad$ (1994) 753-756. http://onlinelibrary.wiley.com/doi/10.1029/93GL03549/full.

[49] J. Tomas, Adhesion of ultrafine particles-A micromechanical approach, Chem. Eng. Sci. 62 (2007) 1997-2010. doi:10.1016/j.ces.2006.12.055. 
[50] A. Russell, J. Schmelzer, P. Müller, M. Krüger, J. Tomas, Mechanical properties and failure probability of compact agglomerates, Powder Technol. 286 (2015) 546-556. doi:10.1016/j.powtec.2015.08.045. 